\title{
CALIBRAÇÃO DE MÉTODOS DE DETERMINAÇÃO DE FÓSFORO EM SOLOS CULTIVADOS SOB SISTEMA PLANTIO DIRETO ${ }^{(1)}$
}

\author{
Jairo André Schlindwein ${ }^{(2)} \&$ Clesio Gianello ${ }^{(3)}$
}

\begin{abstract}
RESUMO
A mudança no sistema de preparo do solo e cultivo das plantas, do sistema convencional para o plantio direto, na profundidade de amostragem e o aumento de rendimento das culturas, ao longo do tempo podem alterar os teores críticos de $P$, as faixas de fertilidade e as quantidades de fertilizante para as culturas. Este trabalho teve por objetivo calibrar os teores de $\mathbf{P}$ disponível, determinado pelos métodos Mehlich-1, Mehlich-3 e resina de troca iônica, nas culturas de soja, trigo e milho cultivadas no sistema plantio direto, e estimar as doses de $\mathbf{P}$ para a máxima eficiência econômica dessas culturas. Para isso, utilizaram-se amostras de solo e resultados de rendimento de grãos de experimentos em sistema plantio direto, com doses de $\mathbf{P}$, realizados por instituições de ensino, pesquisa e extensão no Rio Grande do Sul. A partir da produção, determinaram-se a curva de calibração, as faixas de fertilidade e as doses de $\mathbf{P}$ para a máxima eficiência econômica. Os resultados indicam que o aumento médio no rendimento de grãos de milho, trigo e soja foi de 47,10, 12,37 e 7,20 kg ha ${ }^{-1} \mathrm{~kg}^{-1} \mathrm{de}_{\mathrm{P}_{2}} \mathrm{O}_{5}$, respectivamente. Os coeficientes de determinação entre o rendimento relativo e os teores de $\mathbf{P}$ no solo aumentaram quando se agruparam os solos por classes texturais e foram maiores na camada de 0-10 cm em relação à de 0-20 cm; os teores críticos de $P$ com o método de Mehlich1 foram de 7,5, 15,0 e 21,0 mg kg-1 na camada de 0-20 cm de profundidade e de 16,0; 28,0 e $40,0 \mathrm{mg} \mathrm{kg}^{-1}$ na camada de $0-10 \mathrm{~cm}$, nas classes texturais 1,2 e 3 , respectivamente. As faixas de fertilidade de $\mathbf{P}$ foram maiores nos métodos de Mehlich-3 e resina, se comparados ao método Mehlich-1. As doses do fertilizante fosfatado para as culturas de soja e milho foram maiores que as atualmente recomendadas para produção de 90 \% do rendimento máximo. Verificou-se que os
\end{abstract}

(1) Parte da Tese de Doutorado do primeiro autor, defendida em julho de 2003. Recebido para publicação em fevereiro de 2008 e aprovado em julho de 2008 .

(2) Professor da Faculdade de Agronomia da Universidade de Rondônia - UNIR. Av. Norte Sul 7300, CEP 98789-000 Rolim de Moura (RO). E-mail: jairojas@unir.br

${ }^{(3)}$ Professor do Departamento de Solos da Universidade Federal do Rio Grande do Sul - UFRGS. Av. Bento Gonçalves 7712, CEP 91540-000 Porto Alegre (RS). E-mail: cgianello@hotmail.com 
teores críticos de $\mathbf{P}$ são maiores em solos cultivados sob sistema plantio direto com soja, trigo e milho tanto na camada de 0-20 cm como na de 0-10 cm de profundidade e que os métodos da resina e Mehlich-3 apresentaram faixas de fertilidade mais amplas do que o método Mehlich-1.

Termos de indexação: faixas de fertilidade, teor crítico de fósforo, adubação fosfatada, Mehlich-1, Mehlich-3, resina de troca iônica.

\title{
SUMMARY: CALIBRATION OF PHOSPHORUS EXTRACTION METHODS IN SOILS CULTIVATED UNDER NO-TILLAGE
}

\begin{abstract}
The change of cultivation systems from conventional to no-tillage, the change in soil sampling depth and the higher crop yields over time can influence the critical P content, fertility ranges and fertilizer doses recommended for crops. The objective of this work was to calibrate the soil $P$ tests, Mehlich-1, Mehlich-3 and anion-exchange (AER) resin for soybean, wheat and corn plants cultivated under no-tillage system, and to estimate the $P$ fertilizer amounts for a maximum economic yield. For this purpose soil samples and yield results from several experiments under no-till and different $P$ doses, conducted by institutions of education, research and extension of the state of Rio Grande do Sul. The calibration curves were fitted using non-linear model functions, and the levels of soil fertility and fertilizer doses for a maximum economic yield were inferred. Results indicate that the average increases in corn, wheat and soybean yields were 47.1, 12.4 and $7.2 \mathrm{~kg} \mathrm{ha}^{-1} \mathrm{~kg}^{-1}$ $\mathrm{P}_{2} \mathrm{O}_{5}$, respectively; the determination coefficients between the relative yield and soil $\mathrm{P}$ concentrations were higher when the soils were separated by texture classes and were highest in the $0-10 \mathrm{~cm}$ than the $0-20 \mathrm{~cm}$ layer; the critical values of $P$, based on Mehlich-1 were 7.5 ; 15.0 and $21.0 \mathrm{mg} \mathrm{kg}^{-1}$ in the $0-20 \mathrm{~cm}$ layer, and of $16.0,28.0$ and $40.0 \mathrm{mg} \mathrm{kg}^{-1}$ in the $0_{-}$ $10 \mathrm{~cm}$ layer in the clay classes 1, 2 and 3, respectively; P fertility ranges were wider by Mehlich3 and AER as compared to Mehlich-1; the quantities of P fertilizer were higher for soybean and corn when compared to the currently recommended quantities. The critical P concentrations are higher in soils under no-tillage with soybean, wheat and corn in the $0-20$ as well as the 0 $10 \mathrm{~cm}$ layer; the fertility ranges by resin and Mehlich-3 were wider than by Mehlich-1; the fertilizer P quantities are higher for soybean and corn grown under no-tillage.
\end{abstract}

Index terms: fertility ranges, critical phosphorus content, phosphorus fertilizers, Mehlich-1, Mehlich-3, ion exchange resin.

\section{INTRODUÇÃO}

A principal finalidade da análise do solo é avaliar a disponibilidade de nutrientes para as plantas e, em caso de deficiência, estimar a quantidade a aplicar de corretivos e fertilizantes de modo racional e econômico. Contudo, a análise de solo é viável somente se apoiada em um programa de calibração dos valores obtidos pelo método analítico com o rendimento das culturas.

Calibrar um método de análise do solo consiste em determinar ou relacionar o teor do elemento no solo (nutriente de plantas), utilizando-se para isso um método de avaliação (análise do solo) com características de plantas (índice de crescimento, teor do nutriente e, ou, rendimento da cultura) cultivadas em campo (Rouse, 1968; Cate \& Nelson, 1973; Anghinoni \& Volkweiss, 1984; Evans, 1987).
As recomendações de adubação e calagem no Rio Grande do Sul e Santa Catarina (CFSRS/SC, 2004) foram elaboradas para os sistemas plantio direto e convencional de cultivo com base em estudos de calibração de $\mathrm{P}, \mathrm{K}$ e $\mathrm{N}$, feitos com as culturas cultivadas no sistema convencional, do final da década de 1960 a meados da década de 1980 e nos conhecimentos acumulados até sua edição. Devido a isso, há dúvidas quanto à atualização delas (Schlindwein \& Gianelo, 2004, 2005). Introduziramse, nos últimos anos, mudanças significativas nos sistemas de cultivo, destacando-se que a maior parte das áreas de produção com soja, trigo e milho cultivadas no RS está sob sistema plantio direto; a profundidade de amostragem do solo sob sistema plantio direto é feita na camada de maior concentração de nutrientes $(0-10 \mathrm{~cm})$; o rendimento médio das principais culturas aumentou ao longo do tempo; e o 
método de análise de solo em uso (Mehlich-1) não é adequado para avaliar $\mathrm{P}$ em solos que receberam fosfatos naturais - atualmente existem métodos alternativos e eficientes, de baixo custo e com praticidade laboratorial que também podem ser utilizados.

Uma das principais diferenças entre o sistema convencional de cultivo e o sistema plantio direto é que neste ocorre concentração superficial e subsuperficial de P, K, matéria orgânica e outros nutrientes, decorrente das adubações e da reciclagem de nutrientes (Eltz et al., 1989; Schlindwein \& Anghinoni, 2000). A retirada de amostras de solo da camada de $0-10 \mathrm{~cm}$ de profundidade, com maior concentração em $\mathrm{P}$ e $\mathrm{K}$, proporciona valor maior no resultado da análise do solo desses nutrientes, sem que necessariamente ocorra aumento de rendimento das culturas (Schlindwein \& Anghinoni, 2000). Assim, de acordo com essa lógica, o teor crítico de $\mathrm{P}$ deveria ser maior na camada de $0-10 \mathrm{~cm}$ em solos sob sistema plantio direto do que na de $0-20 \mathrm{~cm}$, tanto sob sistema plantio direto quanto sob sistema convencional de cultivo.

A produtividade das culturas aumentou muito após a realização dos estudos de calibração feitos entre as décadas de 1960 e 1980, tanto em resultados de experimentos quanto de lavoura. Em lavoura, entre as décadas de 1960 até 2005 , a produtividade média das culturas aumentou no RS em 71,174 e $147 \%$ para a soja, trigo e milho, respectivamente (Emater/ RS, 1998, 2005; IBGE, 2005). Esses aumentos podem ser devidos à utilização de variedades mais produtivas e, ou, a técnicas mais avançadas de produção. Entretanto, a exigência de nutrientes também aumentou com a maior exportação de nutrientes. Com isso, além do provável maior teor crítico, também poderá ser necessária dose maior de fertilizantes.

Nos últimos anos, houve aumento da utilização de fosfatos naturais na adubação, principalmente nos solos cultivados sob sistema plantio direto. $\mathrm{O}$ método Mehlich-1, utilizado por todos os laboratórios de rotina de análises de solos do sul do País, é composto por solução diluída de ácidos fortes, cuja reação com o fosfato natural é intensa, superestimando a quantidade de P disponível nessas lavouras (Raij, 1991; Kroth, 1998). Além disso, o método Mehlich-1 extrai menos $\mathrm{P}$ de solos muito argilosos e pode subestimar a sua disponibilidade. Isso pode ocorrer devido à neutralização parcial da solução extratora e, ou, pela readsorção do P extraído (Kamprath \& Watson, 1980), propiciando, às vezes, baixos coeficientes de determinação entre os teores no solo e características de planta (Anghinoni \& Volkweiss, 1984).

Uma característica importante do método de avaliação de nutriente para as plantas é a obtenção de valores relativamente elevados do nutriente do solo. Quanto maior, melhor, pois diminui a possibilidade do erro analítico e aumenta a acuracidade da estimativa de fertilizante. Na comparação do método
Mehlich-1 com os métodos Mehlich-3 e resina de troca iônica, estes últimos extraem mais $\mathrm{P}$, logo poderiam ser melhores do que aquele. Além disso, esses métodos têm apresentado, com freqüência, coeficientes de determinação maiores do que os do método Mehlich-1 (Raij et al., 1986, 1990; Miola, 1995; Braida et al., 1996; Silva et al., 1997; Kroth, 1998; Schlindwein, 2003).

Este trabalho teve por objetivo calibrar (relacionar) os valores do nutriente $\mathrm{P}$ no solo, determinados pelos métodos Mehlich-1, Mehlich-3 e resina de troca iônica, com o rendimento das culturas da soja, do trigo e do milho, cultivadas sob sistema plantio direto e, a partir da estimativa do teor crítico de $\mathrm{P}$ e do estabelecimento de faixas de fertilidade deste no solo, sugerir as doses dos fertilizantes fosfatados para essas culturas no Rio Grande do Sul.

\section{MATERIAL E MÉTODOS}

Os experimentos utilizados neste estudo foram realizados por diferentes instituições de ensino, pesquisa e cooperativas no Rio Grande do Sul e em vários tipos de solo. Os experimentos apresentavam diferentes épocas de cultivo, tempo de condução, delineamento experimental, tratamentos e objetivos da própria instituição. Foram utilizados os experimentos dos quais foi possível obter as amostras de solo dos tratamentos com doses crescentes de P (sendo a doze zero e a do rendimento máximo as mais importantes) e os respectivos dados de rendimento de plantas cultivadas sob sistema plantio direto.

Um experimento foi instalado na Estação Experimental Agronômica da UFRGS, em Eldorado do Sul, em 1995, e conduzido até 1997, sendo cultivado com trigo e milho, inicialmente sob sistema convencional de cultivo e sob sistema plantio direto nos últimos cultivos. A adubação fosfatada (doses de $0,35,70,105,140,120,155,190,228$ e $260 \mathrm{~kg} \mathrm{ha}^{-1}$ de $\mathrm{P}_{2} \mathrm{O}_{5}$ ) foi feita a lanço, com incorporação no solo antes do primeiro cultivo. Em outro experimento, também na Estação Experimental Agronômica da UFRGS, foi cultivado milho sob sistema plantio direto com $\mathrm{P}$ (doses de 0, 62, 123, 246 e $492 \mathrm{~kg} \mathrm{ha}^{-1} \mathrm{P}_{2} \mathrm{O}_{5}$ ) aplicado na superfície antes da semeadura em 2000 e reaplicado também na superfície, em 2001, antes do cultivo de trigo.

Os experimentos nas cooperativas (COTRISOJA, COTRIJAL, COTREL, COPALMA, COTRIJUI, COTRIPAL) em convênio com a FUNDACEP foram realizados com o mesmo delineamento fatorial (4 x 4), composto por culturas e doses de $\mathrm{P}_{2} \mathrm{O}_{5}$ aplicado sempre a lanço. No fator dose de $\mathrm{P}_{2} \mathrm{O}_{5}$, os tratamentos foram compostos por testemunha com zero de $\mathrm{P}_{2} \mathrm{O}_{5}$, quantidades de $\mathrm{P}_{2} \mathrm{O}_{5}$ exportadas pelos grãos, 1 vez e 1,5 vez a dose de $\mathrm{P}_{2} \mathrm{O}_{5}$ recomendada pela CFSRS/SC, (1995). No fator cultura, os tratamentos foram 
compostos por parcela da seqüência soja/trigo e três parcelas da seqüência soja/aveia-preta, soja/aveiapreta+ervilhaca e milho/trigo (rotação de inverno e de verão em diferentes etapas, de modo a ter todas as culturas em todos os anos). Os experimentos foram realizados entre 1999 e 2001.

Dois experimentos foram realizados pela EmbrapaTrigo de Passo Fundo sob sistema plantio direto. $\mathrm{O}$ primeiro foi instalado em 1994 no município de Marau$\mathrm{RS}$, com P (doses de 0, 40, 80, 160 e $320 \mathrm{~kg} \mathrm{ha}^{-1} \mathrm{P}_{2} \mathrm{O}_{5}$ ) incorporado ao solo antes do plantio de trigo e soja. $\mathrm{O}$ outro foi instalado em Passo Fundo em 2000, com P (doses de 0, 50, 100 e $400 \mathrm{~kg} \mathrm{ha}^{-1} \mathrm{P}_{2} \mathrm{O}_{5}$ ) incorporado antes do cultivo das culturas de trigo, soja, cevada e milho.

Os experimentos em Santo Ângelo e em Cruz Alta foram instalados em 1994 e conduzidos sob sistema plantio direto pelas empresas COTRISA e FUNDACEP. O P (doses de 0, 30, 60, 90 e $120 \mathrm{~kg} \mathrm{ha}^{-1} \mathrm{P}_{2} \mathrm{O}_{5}$ ) foi aplicado superficialmente a lanço e incorporado nas parcelas principais antes da cultura de trigo. Após a colheita do trigo, em cada parcela principal, foram aplicadas doses de $\mathrm{P}$ correspondentes a $0,1 / 3,2 / 3,3 /$ 3 e 4/3 da dose de $\mathrm{P}_{2} \mathrm{O}_{5}$ recomendada pela CFSRS/SC (1995), consistindo nas subparcelas cultivadas com as espécies milho e soja, entre 1994 e 2001.

Seis experimentos foram realizados pela cooperativa COTRIJUI e um pela cooperativa COTRIBÁ, sob sistema plantio direto, cultivados com soja em 2001/02, em parcelas grandes $\left(81 \mathrm{~m}^{2}\right) \mathrm{com}$ doses de $\mathrm{P}\left(0,300\right.$ e $\left.600 \mathrm{~kg} \mathrm{ha}^{-1} \mathrm{P}_{2} \mathrm{O}_{5}\right)$ aplicadas a lanço na superfície antes do cultivo da soja.

As amostras de solo de todos os experimentos foram retiradas com pá-de-corte, nas camadas de 0-20 e 0$10 \mathrm{~cm}$ de profundidade e com tamanho de $10 / 5 \mathrm{~cm}$ de largura/espessura. Após a coleta, foram secas a 40 $45^{\circ} \mathrm{C}$ em estufa com circulação forçada de ar, moídas em moinho-martelo e tamisadas em peneira de $2 \mathrm{~mm}$. Nos tratamentos-testemunha de cada experimento, com dose zero de fertilizante, o $\mathrm{P}$ foi determinado pelos métodos Mehlich-1 e resina, conforme procedimentos descritos em Tedesco et al. (1995), e pelo método Mehlich-3, conforme procedimento descrito por Mehlich (1984). Os métodos Mehlich-3 e resina foram adaptados por Schlindwein (2003). Todos os procedimentos de laboratório foram feitos em duplicata, sendo utilizados os dados médios na apresentação dos resultados.

Os resultados de rendimento de grãos das culturas de soja, trigo e milho dos experimentos utilizados neste estudo foram obtidos a partir de colheitas feitas pelas instituições que os conduziram. As análises de regressão das funções de produção entre as doses de $\mathrm{P}$ aplicados no solo e o rendimento de grãos das culturas, em cada ano de avaliação, foram calculadas com os programas SIGMAPLOT e SIGMASTAT, utilizandose equações polinomiais de primeiro e segundo graus, que proporcionaram o melhor ajuste dos dados pelo método dos quadrados mínimos. Nas análises de regressão dos experimentos em que houve o cultivo de várias culturas com uma única aplicação de fertilizantes, foram utilizadas as mesmas doses para todos os cultivos. Para os experimentos que receberam mais de uma aplicação de fertilizantes, foi utilizado o somatório das doses aplicadas até a avaliação da cultura.

O rendimento relativo das culturas em cada ano de avaliação foi determinado a partir da produção obtida das respostas destas nos experimentos com doses de P (Equação 1). A curva de calibração foi feita com os rendimentos relativos de todos os experimentos em cada ano de avaliação e com o teor de $\mathrm{P}$ do tratamento sem o uso do fertilizante fosfatado, determinado pelos diferentes métodos.

$R R(\%)=\frac{\text { Rendimento da cultura sem o fertilizante testado }}{\text { Rendimento máximo da cultura para a dose do fertilizante testado }} \times 100$

A escolha da função utilizada no ajuste dos dados da curva de calibração foi feita pelo programa de computação "TABLE CURVE 2D v 5" da Systat Software Inc. (1999). A equação selecionada (y= a + $\mathrm{b} \ln \mathrm{x}$ ) foi a que melhor se ajustou à maioria dos dados, passa próximo da origem e apresenta formato curvilinear, semelhante ao obtido na resposta das plantas ao teor de nutriente no solo.

O teor crítico foi definido como o teor de nutriente no solo capaz de propiciar 90 \% do rendimento máximo da cultura; esse mesmo procedimento foi utilizado para definir os teores críticos de nutrientes nos Programas de Adubação no RS e SC (Mielniczuk et al., 1969 a, b; UFRGS, 1973; Tabelas..., 1976; Manual..., 1981; Siqueira et al., 1987; CFSRS/SC, 1989, 1995) e em SP (Raij et al., 1997). As faixas de fertilidade de teores de $\mathrm{P}$ foram ajustadas para valores eqüidistantes, com o objetivo de facilitar as interpretações das análises de solo para as futuras recomendações e denominadas "muito baixo", "baixo" e "médio" (abaixo do teor crítico) e "alto" e "muito alto" (acima do teor crítico). Com esse procedimento, foram estabelecidos os novos teores críticos próximos a $90 \%$ do rendimento máximo.

As doses de fertilizantes $\mathrm{P}_{2} \mathrm{O}_{5}$ sugeridas para as futuras adubações das culturas de soja, trigo e milho, nas faixas de teores, foram estabelecidas conforme método utilizado por Kussow et al. (1976). As doses do fertilizante fosfatado que propiciaram $90 \%$ do rendimento máximo de grãos nas funções de produção nos experimentos descritos anteriormente também, teoricamente, devem ter elevado o teor de $\mathrm{P}$ no solo até próximo do teor crítico, pelo menos no cultivo avaliado. Assim, a dose do nutriente $\mathrm{P}_{2} \mathrm{O}_{5}$ aplicada no experimento correspondente ao rendimento de $90 \%$ foi obtida resolvendo-se a equação para a variável " $x$ " das funções de produção $\left(y=a+b x+c x^{2}\right)$. A diferença entre o teor crítico definido na curva de calibração e o teor original de $\mathrm{P}$ do solo no tratamento sem fertilizante testado foi dividida pela quantidade de fertilizante necessária para se obter o rendimento de $90 \%$ das culturas avaliadas. O resultado equivale a quilos de $\mathrm{P}_{2} \mathrm{O}_{5}$ para elevar o teor de $\mathrm{P}$ em $1 \mathrm{mg} \mathrm{kg}^{-1}$ de solo para cada método e profundidade de amostragem. 
As doses de $\mathrm{P}_{2} \mathrm{O}_{5}$ estabelecidas para cada faixa de teor é um valor numérico médio dos métodos (Mehlich-1, Mehlich-3 e resina) e das profundidades de amostragem $(0-20$ e $0-10 \mathrm{~cm})$ e foram calculadas pela diferença entre o valor do teor crítico e o valor intermediário da faixa de teor do nutriente, multiplicado pela quantidade em kg necessária para elevar o teor de $\mathrm{P}_{2} \mathrm{O}_{5}$ em $1 \mathrm{mg} \mathrm{kg}^{-1}$ de solo (Kussow et al., 1976). Esse procedimento foi adotado para cada método e profundidade de amostragem; e em seguida, foi calculada a dose média de fertilizantes nas sugestões para as futuras adubações.

\section{RESULTADOS E DISCUSSÃO}

Os coeficientes das equações de regressão polinomial, os coeficientes de determinação e o rendimento relativo das culturas à adição de fertilizantes estão descritos n o quadro 1; as equações foram selecionadas pelo maior coeficiente de determinação a partir dos rendimentos médios das diferentes culturas, locais e anos de cultivo.

Os rendimentos de grãos de soja e milho, obtidos nos experimentos em parcelas testemunha, ou seja, sem o fertilizante em estudo (coeficiente "a" da função de produção), são em média superiores aos rendimentos médios do RS nas safras 2001, 2002 e 2003, e o trigo, um pouco inferior $\left(1.939,1.770\right.$ e $3.140 \mathrm{~kg} \mathrm{ha}^{-1}$ para a soja, trigo e milho, respectivamente, IBGE, 2005). Isso indica que, em muitos casos, os solos utilizados nos experimentos são representativos do estado de fertilidade dos solos no RS.

A soja foi a cultura que menos respondeu à aplicação de fertilizantes e aumentou em média $7,20 \mathrm{~kg}$ de grãos para cada $\mathrm{kg}$ de $\mathrm{P}_{2} \mathrm{O}_{5}$ adicionado ao solo. O trigo teve respostas intermediárias, com aumento médio de $12,37 \mathrm{~kg}$ de grãos para cada $\mathrm{kg}$ de $\mathrm{P}_{2} \mathrm{O}_{5}$ adicionado ao solo. $\mathrm{O}$ milho teve o maior aumento: em média, 47,10 kg de grãos para cada kg de $\mathrm{P}_{2} \mathrm{O}_{5}$ adicionado ao solo (Quadro 1).

A soja necessita mais $\mathrm{P}_{2} \mathrm{O}_{5}$ para a produção de $1 \mathrm{t}^{-1}$ de grãos, se comparada às culturas de trigo e milho. Esses dados estão de acordo com Raij et al. (1997), que indica a necessidade de 36,6, 13,7 e 11,4 kg de $\mathrm{P}_{2} \mathrm{O}_{5}$ por tonelada de grãos de soja, trigo e milho, respectivamente. A quantidade exportada de $\mathrm{P}_{2} \mathrm{O}_{5}$ pelos grãos também é maior para cultura da soja, se comparada às quantidades para o trigo e para o milho (Raij et al., 1997; CFSRS/SC, 2004).

A eficiência agronômica dos fertilizantes é, portanto, maior para o milho e menor para a soja. No entanto, ao se implantar uma lavoura, considera-se o aspecto econômico; nesse caso, a cultura da soja é mais eficiente, devido ao valor de mercado do grão produzido, ao baixo custo de implantação e condução da lavoura e ao menor risco de frustração de safra, se comparada às culturas de trigo e milho (FECOAGRO/RS, 2004).
Os coeficientes de determinação entre o rendimento e as doses crescentes do nutriente em estudo foram altos para a maioria dos resultados e, em média, maiores do que 0,70 .

As funções das curvas de calibração e os teores críticos de $\mathrm{P}$ foram determinados pelos métodos Mehlich-1, Mehlich-3 e resina de troca iônica, em amostras de solo das camadas de 0-20 e 0-10 cm de profundidade (Quadro 2). As funções e os teores críticos foram estimados pelos teores de $\mathrm{P}$ do solo sem a adição do nutriente testado com o rendimento relativo de $90 \%$, a partir do quadro 1 .

O teor crítico de $\mathrm{P}$ obtido pelo método Mehlich-1, para todos os solos na profundidade de $0-20 \mathrm{~cm}$, foi de $16,6 \mathrm{mg} \mathrm{kg}^{-1}$ (Quadro 2), valor próximo à média $\left(12,0 \mathrm{mg} \mathrm{kg}^{-1}\right)$ dos teores críticos de $\mathrm{P}$ das quatro classes de argila estabelecidos pela CFSRS/SC (2004). Por sua vez, o teor crítico de 25,7 $\mathrm{mg} \mathrm{kg}^{-1}$ (Quadro 2) obtido para método da resina de troca iônica, para todos os solos, independentemente do fator argila, é superior ao teor crítico de $20 \mathrm{mg} \mathrm{kg}^{-1}$ estabelecido pela CFSRS/SC (2004) e muito menor que o teor de $40 \mathrm{mg} \mathrm{kg}^{-1}$ de solo utilizado no Estado de SP para o mesmo método (Raij et al., 1997).

O teor de argila do solo, devido à sua influência na extração do $\mathrm{P}$ disponível pelo método Mehlich-1, é considerado na elaboração das tabelas de recomendação de adubação para os Estados do RS e SC (Mielniczuk et al., 1969; UFRGS, 1973; Tabelas..., 1976; Manual..., 1981; Siqueira et al., 1987; CFSRS/SC, 1989, 1995, 2004). Neste trabalho os solos foram agrupados por classes texturais 1, 2 e 3, com teores de argila $>550$, 550-400 e 400-110 $\mathrm{g} \mathrm{kg}^{-1}$ respectivamente, semelhante aos teores usados pela CFSRS/SC (1995). Os teores críticos de $\mathrm{P}$ obtidos para o método Mehlich-1, na profundidade de $0-20 \mathrm{~cm}$, foram de $7,6,16,8 \mathrm{e}$ 19,2 $\mathrm{mg} \mathrm{kg}^{-1}$ (Quadro 3), contra 6, 9 e $12 \mathrm{mg} \mathrm{kg}^{-1}$ estabelecidos pela CFSRS/SC $(1995,2004)$. A CFSRS/ SC (2004) manteve os mesmos teores críticos da CFSRS/SC (1995), porém modificou os intervalos dos teores de argila nas classes texturais, a saber: $>600$, 600-400, 400-200 e <200 $\mathrm{g} \mathrm{kg}^{-1}$ de argila para as classes 1, 2, 3 e 4, respectivamente. A diferença entre os teores para solos da classe de argila 1 é relativamente pequena $\left(1,2 \mathrm{mg} \mathrm{kg}^{-1}\right)$; a maior diferença ocorreu nos solos da classe 2 .

Os resultados mostram que o teor crítico de $\mathrm{P}$ no solo pelo método Mehlich-1, para o rendimento de aproximadamente $90 \%$ do rendimento máximo das culturas cultivadas sob sistema plantio direto, é, em média, maior que o teor crítico estabelecido pela CFSRS/SC (1995, 2004), com base nas calibrações realizadas entre 1969 e 1980, sob sistema convencional de cultivo. Isso pode ocorrer devido ao maior potencial de rendimento das culturas, ao melhoramento genético e, ou, à seleção de cultivares visando a aumentos de produtividade. O rendimento médio das culturas tem aumentado ao longo dos anos nas lavouras do RS (Emater/RS, 1998, 2005; IBGE, 2005); 
Quadro 1. Instituição condutora dos experimentos no RS, ano de condução, equação de regressão polinomial, coeficiente de determinação e rendimento relativo das culturas soja, trigo e milho cultivadas sob sistema plantio direto com doses de $\mathrm{P}_{2} \mathrm{O}_{5}$

\begin{tabular}{|c|c|c|c|c|}
\hline Instituição & Ano & Equação de regressão polinomial & $\mathbf{R}^{2}$ & $\begin{array}{l}\text { Rendimento } \\
\text { relativo }\end{array}$ \\
\hline \multicolumn{4}{|c|}{ Soja } & $\%$ \\
\hline COTRIJUI (Ajuricaba) & 2002 & $\hat{\mathrm{y}}=3507+0,25\left(\mathrm{P}_{2} \mathrm{O}_{5}\right)$ & 0,49 & 96 \\
\hline COTRIJUI (C.Bicaco) & 2002 & $\hat{\mathrm{y}}=2833-0,04\left(\mathrm{P}_{2} \mathrm{O}_{5}\right)$ & 0,04 & 100 \\
\hline COTRIJUI (Redentora) & 2002 & $\hat{\mathrm{y}}=2500-0,04\left(\mathrm{P}_{2} \mathrm{O}_{5}\right)$ & 0,43 & 100 \\
\hline COTRIJUI (S. Augusto) & 2002 & $\hat{\mathrm{y}}=2532-0,85\left(\mathrm{P}_{2} \mathrm{O}_{5}\right)$ & 0,87 & 100 \\
\hline COTRIBÁ (Ibirubá) & 2002 & $\hat{\mathrm{y}}=3474+0,08\left(\mathrm{P}_{2} \mathrm{O}_{5}\right)$ & 0,43 & 99 \\
\hline COTRIJUI (S. Valério) & 2002 & $\hat{\mathrm{y}}=3049+1,01\left(\mathrm{P}_{2} \mathrm{O}_{5}\right)$ & 0,93 & 88 \\
\hline COTRIJUI (S. Valério) & 2002 & $\hat{\mathrm{y}}=2055+0,78\left(\mathrm{P}_{2} \mathrm{O}_{5}\right)$ & 0,55 & 88 \\
\hline COTRISOL - FUNDACEP & 1999 & $\hat{\mathrm{y}}=3670+29,80\left(\mathrm{P}_{2} \mathrm{O}_{5}\right)-0,590\left(\mathrm{P}_{2} \mathrm{O}_{5}\right)^{2}$ & 0,99 & 91 \\
\hline COTRISOL - FUNDACEP & 2000 & $\hat{\mathrm{y}}=2587+9,36\left(\mathrm{P}_{2} \mathrm{O}_{5}\right)-0,060\left(\mathrm{P}_{2} \mathrm{O}_{5}\right)^{2}$ & 0,96 & 83 \\
\hline COTRISOL - FUNDACEP & 2001 & $\hat{\mathrm{y}}=1409+9,22\left(\mathrm{P}_{2} \mathrm{O}_{5}\right)-0,005\left(\mathrm{P}_{2} \mathrm{O}_{5}\right)^{2}$ & 0,99 & 73 \\
\hline COTRIJAL - FUNDACEP & 1999 & $\hat{\mathrm{y}}=2033+13,50\left(\mathrm{P}_{2} \mathrm{O}_{5}\right)-0,100\left(\mathrm{P}_{2} \mathrm{O}_{5}\right)^{2}$ & 0,84 & 87 \\
\hline COTRIJAL - FUNDACEP & 2000 & $\hat{\mathrm{y}}=2881+9,90\left(\mathrm{P}_{2} \mathrm{O}_{5}\right)$ & 0,71 & 83 \\
\hline COTRIJAL - FUNDACEP & 2001 & $\hat{\mathrm{y}}=1831+10,88\left(\mathrm{P}_{2} \mathrm{O}_{5}\right)-0,080\left(\mathrm{P}_{2} \mathrm{O}_{5}\right)^{2}$ & 0,93 & 83 \\
\hline COTREL - FUNDACEP & 1999 & $\hat{\mathrm{y}}=1885+14,48\left(\mathrm{P}_{2} \mathrm{O}_{5}\right)-0,240\left(\mathrm{P}_{2} \mathrm{O}_{5}\right)^{2}$ & 0,79 & 90 \\
\hline COPALMA - FUNDACEP & 1999 & $\hat{\mathrm{y}}=325+2,35\left(\mathrm{P}_{2} \mathrm{O}_{5}\right)-0,005\left(\mathrm{P}_{2} \mathrm{O}_{5}\right)^{2}$ & 0,98 & 62 \\
\hline Embrapa Trigo (Marau) & 1994 & $\hat{\mathrm{y}}=1942+12,54\left(\mathrm{P}_{2} \mathrm{O}_{5}\right)-0,020\left(\mathrm{P}_{2} \mathrm{O}_{5}\right)^{2}$ & 0,92 & 60 \\
\hline Embrapa Trigo & 2000 & $\hat{\mathrm{y}}=1486+12,44\left(\mathrm{P}_{2} \mathrm{O}_{5}\right)-0,020\left(\mathrm{P}_{2} \mathrm{O}_{5}\right)^{2}$ & 0,94 & 55 \\
\hline COTRIUI -FUNDACEP & 2001 & $\hat{\mathrm{y}}=2335+9,46\left(\mathrm{P}_{2} \mathrm{O}_{5}\right)-0,020\left(\mathrm{P}_{2} \mathrm{O}_{5}\right)^{2}$ & 0,99 & 82 \\
\hline COTRIPAL - FUNDACEP & 2001 & $\hat{\mathrm{y}}=1547+9,53\left(\mathrm{P}_{2} \mathrm{O}_{5}\right)-0,020\left(\mathrm{P}_{2} \mathrm{O}_{5}\right)^{2}$ & 0,85 & 68 \\
\hline COTRISA - FUNDACEP & 1994 & $\hat{\mathrm{y}}=2766+3,06\left(\mathrm{P}_{2} \mathrm{O}_{5}\right)$ & 0,42 & 89 \\
\hline COTRISA - FUNDACEP & 2000 & $\hat{\mathrm{y}}=2318+20,25\left(\mathrm{P}_{2} \mathrm{O}_{5}\right)-0,120\left(\mathrm{P}_{2} \mathrm{O}_{5}\right)^{2}$ & 0,39 & 73 \\
\hline FUNDACEP & 1994 & $\hat{\mathrm{y}}=2908+1,54\left(\mathrm{P}_{2} \mathrm{O}_{5}\right)-0,007\left(\mathrm{P}_{2} \mathrm{O}_{5}\right)^{2}$ & 0,02 & 97 \\
\hline FUNDACEP & 1995 & $\hat{\mathrm{y}}=2441+2,67\left(\mathrm{P}_{2} \mathrm{O}_{5}\right)-0,020\left(\mathrm{P}_{2} \mathrm{O}_{5}\right)^{2}$ & 0,02 & 96 \\
\hline FUNDACEP & 1997 & $\hat{\mathrm{y}}=2975+1,70\left(\mathrm{P}_{2} \mathrm{O}_{5}\right)-0,020\left(\mathrm{P}_{2} \mathrm{O}_{5}\right)^{2}$ & 0,02 & 96 \\
\hline FUNDACEP & 2000 & $\hat{\mathrm{y}}=2923+6,02\left(\mathrm{P}_{2} \mathrm{O}_{5}\right)-0,190\left(\mathrm{P}_{2} \mathrm{O}_{5}\right)^{2}$ & 0,19 & 93 \\
\hline Média & & $\hat{\mathrm{y}}=2408+7,20\left(\mathrm{P}_{2} \mathrm{O}_{5}\right)-0,10\left(\mathrm{P}_{2} \mathrm{O}_{5}\right)^{2}$ & 0,63 & 85 \\
\hline \multicolumn{5}{|c|}{ Trigo } \\
\hline UFRGS & 1996 & $\hat{\mathrm{y}}=1013+14,8\left(\mathrm{P}_{2} \mathrm{O}_{5}\right)-0,035\left(\mathrm{P}_{2} \mathrm{O}_{5}\right)^{2}$ & 0,93 & 40 \\
\hline UFRGS & 1997 & $\hat{\mathrm{y}}=1447+7,38\left(\mathrm{P}_{2} \mathrm{O}_{5}\right)-0,016\left(\mathrm{P}_{2} \mathrm{O}_{5}\right)^{2}$ & 0,98 & 64 \\
\hline COTRISOL - FUNDACEP & 2000 & $\hat{\mathrm{y}}=2591+52,80\left(\mathrm{P}_{2} \mathrm{O}_{5}\right)-1,110\left(\mathrm{P}_{2} \mathrm{O}_{5}\right)^{2}$ & 0,99 & 80 \\
\hline COTRIJAL - FUNDACEP & 2000 & $\hat{\mathrm{y}}=1147+25,69\left(\mathrm{P}_{2} \mathrm{O}_{5}\right)-0,350\left(\mathrm{P}_{2} \mathrm{O}_{5}\right)^{2}$ & 0,99 & 71 \\
\hline COTREL - FUNDACEP & 2000 & $\hat{\mathrm{y}}=1585+11,45\left(\mathrm{P}_{2} \mathrm{O}_{5}\right)-0,050\left(\mathrm{P}_{2} \mathrm{O}_{5}\right)^{2}$ & 0,73 & 72 \\
\hline Embrapa Trigo (Marau) & 1994 & $\hat{\mathrm{y}}=1376+3,51\left(\mathrm{P}_{2} \mathrm{O}_{5}\right)-0,003\left(\mathrm{P}_{2} \mathrm{O}_{5}\right)^{2}$ & 0,96 & 56 \\
\hline Embrapa Trigo & 2000 & $\hat{\mathrm{y}}=1076+5,03\left(\mathrm{P}_{2} \mathrm{O}_{5}\right)-0,009\left(\mathrm{P}_{2} \mathrm{O}_{5}\right)^{2}$ & 0,99 & 63 \\
\hline Embrapa Trigo & 2001 & $\hat{\mathrm{y}}=1368+8,34\left(\mathrm{P}_{2} \mathrm{O}_{5}\right)-0,010\left(\mathrm{P}_{2} \mathrm{O}_{5}\right)^{2}$ & 0,99 & 53 \\
\hline COTRISA - FUNDACEP & 1999 & $\hat{\mathrm{y}}=950-1,16\left(\mathrm{P}_{2} \mathrm{O}_{5}\right)$ & 0,10 & 100 \\
\hline FUNDACEP & 1997 & $\hat{\mathrm{y}}=2134+5,04\left(\mathrm{P}_{2} \mathrm{O}_{5}\right)-0,020\left(\mathrm{P}_{2} \mathrm{O}_{5}\right)^{2}$ & 0,45 & 85 \\
\hline FUNDACEP & 1999 & $\hat{\mathrm{y}}=2895+3,19\left(\mathrm{P}_{2} \mathrm{O}_{5}\right)-0,020\left(\mathrm{P}_{2} \mathrm{O}_{5}\right)^{2}$ & 0,12 & 96 \\
\hline Média & & $\hat{\mathrm{y}}=1598+12,37\left(\mathrm{P}_{2} \mathrm{O}_{5}\right)-0,160\left(\mathrm{P}_{2} \mathrm{O}_{5}\right)^{2}$ & 0,75 & 71 \\
\hline \multicolumn{5}{|c|}{ Milho } \\
\hline UFRGS & 1996 & $\hat{\mathrm{y}}=3973+48,02\left(\mathrm{P}_{2} \mathrm{O}_{5}\right)-0,125\left(\mathrm{P}_{2} \mathrm{O}_{5}\right)^{2}$ & 0,95 & 46 \\
\hline UFRGS & 1997 & $\hat{\mathrm{y}}=5234+31,82\left(\mathrm{P}_{2} \mathrm{O}_{5}\right)-0,064\left(\mathrm{P}_{2} \mathrm{O}_{5}\right)^{2}$ & 0,90 & 57 \\
\hline UFRGS & 1998 & $\hat{\mathrm{y}}=3732+22,89\left(\mathrm{P}_{2} \mathrm{O}_{5}\right)-0,033\left(\mathrm{P}_{2} \mathrm{O}_{5}\right)^{2}$ & 0,96 & 50 \\
\hline UFRGS & 2000 & $\hat{\mathrm{y}}=6264+24,58\left(\mathrm{P}_{2} \mathrm{O}_{5}\right)-0,040\left(\mathrm{P}_{2} \mathrm{O}_{5}\right)^{2}$ & 0,79 & 60 \\
\hline COTRISOL - FUNDACEP & 1999 & $\hat{\mathrm{y}}=2581+104,44\left(\mathrm{P}_{2} \mathrm{O}_{5}\right)-1,310\left(\mathrm{P}_{2} \mathrm{O}_{5}\right)^{2}$ & 0,99 & 56 \\
\hline COTRISOL - FUNDACEP & 2000 & $\hat{\mathrm{y}}=4225+48,75\left(\mathrm{P}_{2} \mathrm{O}_{5}\right)-1,000\left(\mathrm{P}_{2} \mathrm{O}_{5}\right)^{2}$ & 0,90 & 90 \\
\hline COTRISOL - FUNDACEP & 2001 & $\hat{\mathrm{y}}=3512+14,51\left(\mathrm{P}_{2} \mathrm{O}_{5}\right)-0,130\left(\mathrm{P}_{2} \mathrm{O}_{5}\right)^{2}$ & 0,99 & 73 \\
\hline COTRIJAL - FUNDACEP & 1999 & $\hat{\mathrm{y}}=3468+113,56\left(\mathrm{P}_{2} \mathrm{O}_{5}\right)-2,660\left(\mathrm{P}_{2} \mathrm{O}_{5}\right)^{2}$ & 0,91 & 86 \\
\hline COTRIJAL - FUNDACEP & 2000 & $\hat{\mathrm{y}}=3853+20,96\left(\mathrm{P}_{2} \mathrm{O}_{5}\right)$ & 0,59 & 75 \\
\hline COTRIJAL - FUNDACEP & 2001 & $\hat{\mathrm{y}}=2736+7,27\left(\mathrm{P}_{2} \mathrm{O}_{5}\right)$ & 0,79 & 63 \\
\hline COTREL - FUNDACEP & 1999 & $\hat{\mathrm{y}}=7026+184,64\left(\mathrm{P}_{2} \mathrm{O}_{5}\right)-2,950\left(\mathrm{P}_{2} \mathrm{O}_{5}\right)^{2}$ & 0,87 & 76 \\
\hline COPALMA - FUNDACEP & 1999 & $\hat{\mathrm{y}}=7013+120,72\left(\mathrm{P}_{2} \mathrm{O}_{5}\right)-1,450\left(\mathrm{P}_{2} \mathrm{O}_{5}\right)^{2}$ & 0,94 & 53 \\
\hline
\end{tabular}




\section{Quadro 1. Continuação}

\begin{tabular}{|c|c|c|c|c|}
\hline Instituição & Ano & Equação de regressão polinomial & $\mathbf{R}^{2}$ & $\begin{array}{c}\text { Rendimento } \\
\text { relativo }\end{array}$ \\
\hline \multicolumn{5}{|c|}{ Milho } \\
\hline Embrapa Trigo & 2000 & $\hat{\mathrm{y}}=3196+10,22\left(\mathrm{P}_{2} \mathrm{O}_{5}\right)-0,020\left(\mathrm{P}_{2} \mathrm{O}_{5}\right)^{2}$ & 0,99 & 69 \\
\hline COTRIJUI - FUNDACEP & 2001 & $\hat{\mathrm{y}}=3710+27,70\left(\mathrm{P}_{2} \mathrm{O}_{5}\right)-0,240\left(\mathrm{P}_{2} \mathrm{O}_{5}\right)^{2}$ & 0,96 & 83 \\
\hline COTRIPAL - FUNDACEP & 2001 & $\hat{\mathrm{y}}=2699+16,89\left(\mathrm{P}_{2} \mathrm{O}_{5}\right)-0,040\left(\mathrm{P}_{2} \mathrm{O}_{5}\right)^{2}$ & 0,99 & 69 \\
\hline COTRISA - FUN DACEP & 1996 & $\hat{\mathrm{y}}=4214+30,97\left(\mathrm{P}_{2} \mathrm{O}_{5}\right)-0,180\left(\mathrm{P}_{2} \mathrm{O}_{5}\right)^{2}$ & 0,51 & 76 \\
\hline COTRISA - FUNDACEP & 1998 & $\hat{\mathrm{y}}=940+10,80\left(\mathrm{P}_{2} \mathrm{O}_{5}\right)-0,050\left(\mathrm{P}_{2} \mathrm{O}_{5}\right)^{2}$ & 0,41 & 60 \\
\hline FUNDACEP & 1996 & $\hat{\mathrm{y}}=7939+9,06\left(\mathrm{P}_{2} \mathrm{O}_{5}\right)-0,020\left(\mathrm{P}_{2} \mathrm{O}_{5}\right)^{2}$ & 0,54 & 91 \\
\hline Média & & $\hat{\mathrm{y}}=4239+47,10\left(\mathrm{P}_{2} \mathrm{O}_{5}\right)-0,640\left(\mathrm{P}_{2} \mathrm{O}_{5}\right)^{2}$ & 0,83 & 68 \\
\hline
\end{tabular}

Quadro 2. Equação de ajuste de calibração e teor crítico de fósforo determinado por diferentes métodos e profundidades de amostragem dos solos cultivados com soja, trigo e milho sob sistema plantio direto

\begin{tabular}{|c|c|c|c|}
\hline Método & Profundidade & Equação de ajuste ${ }^{(1)}$ & Teor crítico \\
\hline & $\mathrm{cm}$ & & \\
\hline Mehlich - 1 & $\begin{array}{l}0-20 \\
0-10\end{array}$ & $\begin{array}{l}\hat{y}=48,4+15,5 \ln x \\
\hat{y}=40,2+16,5 \ln x\end{array}$ & $\begin{array}{l}16,6 \\
20,5\end{array}$ \\
\hline Mehlich - 3 & $\begin{array}{l}0-20 \\
0-10\end{array}$ & $\begin{array}{l}\hat{y}=50,5+11,6 \ln x \\
\hat{y}=38,9+14,3 \ln x\end{array}$ & $\begin{array}{l}30,1 \\
35,6\end{array}$ \\
\hline Resina & $\begin{array}{l}0-20 \\
0-10\end{array}$ & $\begin{array}{l}\hat{y}=48,1+12,9 \ln x \\
\hat{y}=37,9+14,9 \ln x\end{array}$ & $\begin{array}{l}25,7 \\
33,0\end{array}$ \\
\hline
\end{tabular}

(1) Os valores de $\mathrm{R}^{2}$ estão no quadro 4.

conseqüentemente, pode ser necessário teor crítico de nutrientes maior do que o estabelecido atualmente. Assim, a quantidade de fertilizante a aplicar para rendimento de $90 \%$ do máximo também seria aumentada (Schlindwein \& Gianello, 2004; 2006).

Se o teor crítico de $\mathrm{P}$ na camada de $0-20 \mathrm{~cm}$ de profundidade, no método Mehlich-1, é maior em solos sob sistema plantio direto do que sob sistema convencional de cultivo (CFSRS/SC, 1995, 2004), na camada de 0-10 $\mathrm{cm}$ de profundidade é maior ainda (Quadro 3). Isso se deve ao maior teor de $\mathrm{P}$ na superfície ou subsuperfície do solo (Eltz et al., 1989; Schlindwein \& Anghinoni, 2000). Os resultados de Schlindwein \& Anghinoni (2000) mostram teor de P aproximadamente $50 \%$ maior na camada de $0-10 \mathrm{~cm}$ do que na de $0-20 \mathrm{~cm}$, em experimentos de longa duração cultivados sob sistema plantio direto.

Os valores de teor crítico de $\mathrm{P}$ dos solos da classe 2 estão mais próximos das classes 3 do que da classe 1 , principalmente nos métodos Mehlich-3 e resina, mostrando o que na prática já se conhece: solos muito argilosos, com alto poder-tampão, apresentam alta capacidade de suprimento de $\mathrm{P}$ às plantas (Kroth, 1998; Schlindwein, 2003). Por sua vez, o método da resina extrai menos $\mathrm{P}$ em solos arenosos se comparado ao método Mehlich-1, para o mesmo suprimento às plantas, provavelmente devido à diminuição da difusão em solos arenosos (Miola, 1995; Kroth, 1998; Schlindwein, 2003). Além disso, o método Mehlich-1 extrai mais de solos arenosos, por causa da menor readsorção de $\mathrm{P}$ e da menor perda de capacidade extrativa (Kamprath \& Watson, 1980).

Os teores críticos de $\mathrm{P}$ obtidos pelos métodos Mehlich-3 e resina foram sempre superiores aos obtidos pelo método Mehlich-1, tanto para os solos agrupados como para separados por classes texturais (Quadros 2 e 3). Essa característica é vantajosa, pois permite o estabelecimento de faixas de fertilidade mais amplas, sugerindo maior acuracidade na interpretação dos resultados e nas recomendações de fertilizantes.

Os coeficientes de determinação, embora significativos para todos os métodos, à exceção do método Mehlich-3 na profundidade de $0-10 \mathrm{~cm}$, foram variáveis e mostram a eficiência dos métodos em quantificar a disponibilidade de nutrientes para determinar o rendimento relativo das plantas (Quadros 4 e 5). O método da resina apresentou o maior coeficiente de determinação na calibração de P (Quadro 5), confirmando os dados obtidos em estudos de casa de vegetação, onde esse método foi equivalente ou superior aos demais (Rein, 1991; Miola, 1995; Braida et al., 1996; Silva, 1996; Kroth, 1998; Schlindwein, 2003). 
Quadro 3. Métodos avaliados, profundidade de amostragem, equação ajustada para diferentes faixas de teor de argila e teor crítico de fósforo para solos cultivados com soja, trigo e milho sob sistema plantio direto

\begin{tabular}{|c|c|c|c|c|}
\hline Método & Profundidade & Argila & Equações de ajuste ${ }^{(1)}$ & Teor crítico \\
\hline & $\mathrm{cm}$ & $\mathrm{g} \mathrm{kg}^{-1}$ & & \\
\hline Mehlich - 1 & 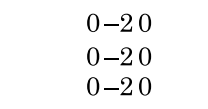 & $\begin{aligned}> & 550 \\
& 550-400 \\
& 400-110\end{aligned}$ & $\begin{array}{l}\hat{y}=39,2+25,1 \ln x \\
\hat{y}=31,2+20,8 \ln x \\
\hat{y}=39,5+17,1 \ln x\end{array}$ & $\begin{array}{r}7,6 \\
16,8 \\
19,2\end{array}$ \\
\hline Mehlich - 1 & $\begin{array}{l}0-10 \\
0-10 \\
0-10\end{array}$ & $\begin{array}{r}>550 \\
550-400 \\
400-110\end{array}$ & $\begin{array}{l}\hat{y}=33,5+24,0 \ln x \\
\hat{y}=35,0+18,4 \ln x \\
\hat{y}=32,4+16,8 \ln x\end{array}$ & $\begin{array}{l}10,5 \\
19,9 \\
30,8\end{array}$ \\
\hline Mehlich - 3 & $\begin{array}{l}0-20 \\
0-20 \\
0-20\end{array}$ & $\begin{array}{r}>550 \\
550-400 \\
400-110\end{array}$ & $\begin{array}{l}\hat{y}=33,8+22,8 \ln x \\
\hat{y}=55,9+10,1 \ln x \\
\hat{y}=42,6+13,0 \ln x\end{array}$ & $\begin{array}{l}11,8 \\
29,3 \\
38,3\end{array}$ \\
\hline Mehlich - 3 & $\begin{array}{l}0-10 \\
0-10 \\
0-10\end{array}$ & $\begin{array}{r}>550 \\
550-400 \\
400-110\end{array}$ & $\begin{array}{l}\hat{y}=41,7+17,9 \ln x \\
\hat{y}=49,7+11,2 \ln x \\
\hat{y}=23,8+17,8 \ln x\end{array}$ & $\begin{array}{l}14,9 \\
36,5 \\
41,2\end{array}$ \\
\hline Resina & 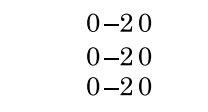 & $\begin{array}{r}>550 \\
550-400 \\
400-110\end{array}$ & $\begin{array}{l}\hat{y}=46,6+15,8 \ln x \\
\hat{y}=51,9+11,8 \ln x \\
\hat{y}=48,7+12,3 \ln x\end{array}$ & $\begin{array}{l}15,6 \\
25,2 \\
28,7\end{array}$ \\
\hline Resina & $\begin{array}{l}0-10 \\
0-10 \\
0-10\end{array}$ & $\begin{aligned}> & 550 \\
& 550-400 \\
& 400-110\end{aligned}$ & $\begin{array}{l}\hat{y}=38,4+18,0 \ln x \\
\hat{y}=35,7+16,7 \ln x \\
\hat{y}=27,5+17,2 \ln x\end{array}$ & $\begin{array}{l}17,6 \\
25,8 \\
37,8\end{array}$ \\
\hline
\end{tabular}

(1) Os valores de $\mathrm{R}^{2}$ estão no quadro 5.

Quadro 4. Coeficiente de determinação entre o fósforo, determinado por diferentes métodos de extração em amostras de solo retiradas das camadas de 0-20 e 0-10 cm de profundidade, e o rendimento relativo das culturas soja, trigo e milho sob sistema plantio direto

\begin{tabular}{lccc}
\hline \multirow{2}{*}{ Método } & \multicolumn{3}{c}{ Profundidade de amostragem } \\
\cline { 2 - 4 } & $\mathbf{0 - 2 0 \mathbf { ~ c m }}$ & $\mathbf{0 - 1 0} \mathbf{~ c m}$ & Média \\
\cline { 2 - 4 } & & $\mathrm{R}^{2}$ & \\
Mehlich-1 & $0,45^{* *}$ & $0,52^{* *}$ & 0,49 \\
Mehlich-3 & $0,45^{* *}$ & $0,40^{* *}$ & 0,43 \\
Resina & $0,56^{* *}$ & $0,55^{* *}$ & 0,56 \\
\hline
\end{tabular}

$*$ : significativo $(p<0,05) ; * *$ : significativo $(p<0,01)$.

Quando os solos foram separados por classes de teores de argila, todos os coeficientes aumentaram, sobretudo nas calibrações realizadas com os solos amostrados na camada de $0-10 \mathrm{~cm}$ de profundidade (Quadro 5). Na camada de 0-20 cm, o coeficiente de determinação obtido com o método da resina foi maior, em relação à camada de $0-10 \mathrm{~cm}$, em que o método Mehlich-1 apresentou maior coeficiente. No entanto, na média geral, ambos os métodos se equivaleram e foram superiores ao método Mehlich-3.

Após a definição do teor crítico de $\mathrm{P}$, para os diferentes métodos de análise e profundidade de amostragem, pode-se detalhar melhor a curva de calibração na parte abaixo desse ponto, estabelecendo- se assim as faixas de fertilidade. Estas podem ser divididas a partir do rendimento relativo, como foi estabelecido nas Recomendações de Adubação e Calagem para o Estado de São Paulo (Raij et al., 1997), ou em teores no solo em quantidades eqüidistantes, como estabelecido no RS (Mielniczuk et al., 1969 a, b; UFGRS, 1973; Manual..., 1981; Siqueira et al., 1987; CFSRS/SC, 1995, 2004). Neste trabalho, as faixas de fertilidade do solo foram ajustadas para valores do teor de $\mathrm{P}$ eqüidistantes e inteiros e denominadas "muito baixo", "baixo", "médio", "alto e muito alto" (Quadro 6). $\mathrm{O}$ valor superior da faixa de teor médio representa 0 teor crítico ajustado.

As quantidades de $\mathrm{P}_{2} \mathrm{O}_{5}$ para produzir $90 \%$ do rendimento máximo e elevar os teores de $\mathrm{P}$ em $1 \mathrm{mg} \mathrm{kg}^{-1}$ de solo (Kussow et al., 1976) são variáveis entre as culturas e os métodos (Quadro 7). Aparentemente, a soja necessita de mais $\mathrm{P}$ do que o trigo e o milho para produzir $90 \%$ do rendimento máximo estimado. Esses dados são confirmados pela maior necessidade de $\mathrm{P}$ para a produção de $1 \mathrm{~kg}$ de grãos (Quadro 1); a soja produz em média apenas 7,2 kg de grãos para cada kg de $\mathrm{P}_{2} \mathrm{O}_{5}$ aplicado no solo, ao passo que o trigo e o milho produzem 12,4 e 47,1 kg de grãos, respectivamente. A soja também é a cultura que mais necessita de $\mathrm{P}_{2} \mathrm{O}_{5}$ na planta inteira para produção de grãos: aproximadamente $36,6 \mathrm{~kg} \mathrm{t}^{-1}$ de grãos, contra $13,2 \mathrm{e}$ $11,4 \mathrm{~kg} \mathrm{t}^{-1}$ de grãos de trigo e milho, respectivamente (Raij et al., 1997). Supondo uma produção média igual a $90 \%$ da produção máxima a partir do quadro $1(2,7$, 2,2 e 5,6 t ha $^{-1}$ de soja, trigo e milho, respectivamente), a necessidade de $\mathrm{P}$ na forma de $\mathrm{P}_{2} \mathrm{O}_{5}$ é de 97,9, 
Quadro 5. Coeficiente de determinação entre o teor de fósforo, determinado por diferentes métodos de extração em amostras de solo retiradas das camadas de 0-20 e 0-10 cm de profundidade em classes texturais, o rendimento relativo das culturas soja, trigo e milho sob sistema plantio direto

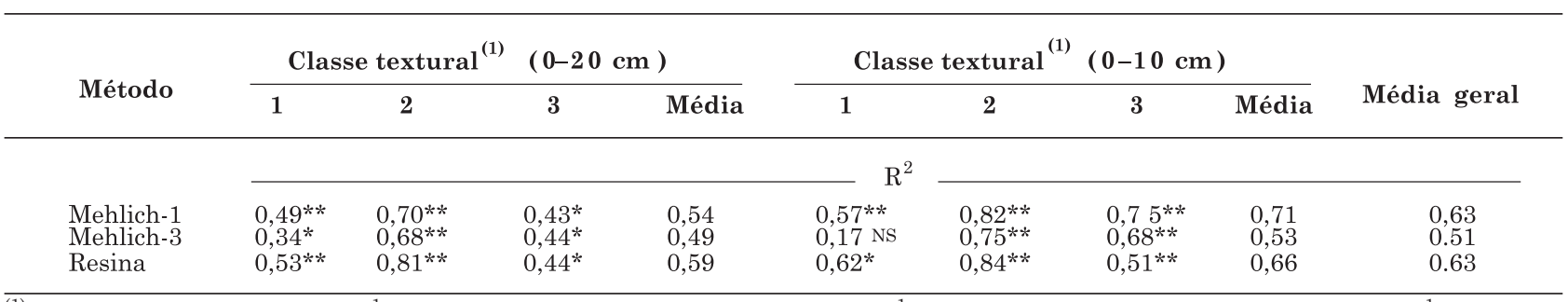

(1) Classe 1, argila > $550 \mathrm{~g} \mathrm{~kg}^{-1}$ de solo; classe 2, argila de 550-400 g kg-1 de solo; classe 3 , argila de $400-110 \mathrm{~g} \mathrm{~kg}^{-1} \mathrm{de}^{-10 l o}$ * Significativo $(p<0,05), * *$ Significativo $(p<0,01)$, NS Não significativo $(p>0,05)$.

Quadro 6. Estabelecimento de faixas de teores de fósforo do solo no sistema plantio direto, determinado pelos métodos Mehlich-1, Mehlich-3 e resina, em amostras de solo da camada de 0-20 e 0-10 cm de profundidade de experimentos localizados no RS, conforme as classes de teor de argila

\begin{tabular}{|c|c|c|c|c|c|c|}
\hline \multirow{2}{*}{ Profundidade } & \multirow{2}{*}{ Classe de argila $^{(1)}$} & \multicolumn{5}{|c|}{ Faixa de fertilidade } \\
\hline & & Muito baixo & Baixo & Médio ${ }^{(2)}$ & Alto & Muito alto \\
\hline \multirow[t]{2}{*}{$\mathrm{cm}$} & & & & $\mathrm{mg} \mathrm{kg} \cdot 1$ & & \\
\hline & & & & Mehlich - 1 & & \\
\hline \multirow[t]{3}{*}{$0-20$} & 1 & $0-2,5$ & $2,6-5,0$ & $5,1-7,5$ & $7,6-10,0$ & $>10,0$ \\
\hline & 2 & $0-5,0$ & $5,1-10,0$ & $10,1-15,0$ & $15,1-20,0$ & $>20,0$ \\
\hline & 3 & $0-7,0$ & $7,1-14,0$ & $14,1-21,0$ & $21,1-28,0$ & $>28,0$ \\
\hline \multirow[t]{3}{*}{$0-10$} & 1 & $0-4,0$ & $4,1-8,0$ & $8,1-12,0$ & $12,1-16,0$ & $>16,0$ \\
\hline & 2 & $0-7,0$ & $7,1-14,0$ & $14,1-21,0$ & $21,1-28,0$ & $>28,0$ \\
\hline & 3 & $0-10,0$ & $10,1-20,0$ & $20,1-30,0$ & $30,1-40,0$ & $>40,0$ \\
\hline \multirow{4}{*}{$0-20$} & & & & Mehlich - 3 & & \\
\hline & 1 & $0-4,0$ & $4,1-8,0$ & $8,1-12,0$ & $12,1-16,0$ & $>16,0$ \\
\hline & 2 & $0-10,0$ & $10,1-20,0$ & $20,1-30,0$ & $30,1-40,0$ & $>40,0$ \\
\hline & 3 & $0-15,0$ & $15,1-30,0$ & $30,1-45,0$ & $45,1-60,0$ & $>60,0$ \\
\hline \multirow[t]{4}{*}{$0-10$} & 1 & $0-5,0$ & $5,1-10,0$ & $10,1-15,0$ & $15,1-20,0$ & $>20,0$ \\
\hline & 2 & $0-12,0$ & $12,1-24,0$ & $24,1-36,0$ & $36,1-48,0$ & $>48,0$ \\
\hline & 3 & $0-20,0$ & $20,1-40,0$ & $40,1-60,0$ & $60,1-80,0$ & $>80,0$ \\
\hline & & & & Resina & & \\
\hline \multirow[t]{3}{*}{$0-20$} & 1 & $0-5,0$ & $5,1-10,0$ & $10,1-15,0$ & $15,1-20,0$ & $>20,0$ \\
\hline & 2 & $0-8,0$ & $8,1-16,0$ & $16,1-24,0$ & $24,1-32,0$ & $>32,0$ \\
\hline & 3 & $0-10,0$ & $10,1-20,0$ & $20,1-30,0$ & $30,1-40,0$ & $>40,0$ \\
\hline \multirow[t]{3}{*}{$0-10$} & 1 & $0-7,0$ & $7,1-14,0$ & $14,1-21,0$ & $21,1-28,0$ & $>28,0$ \\
\hline & 2 & $0-10,0$ & $10,1-20,0$ & $20,1-30,0$ & $30,1-40,0$ & $>40,0$ \\
\hline & 3 & $0-12,0$ & $12,1-24,0$ & $24,1-36,0$ & $36,1-48,0$ & $>48,0$ \\
\hline
\end{tabular}

(1) Classe 1, argila > $550 \mathrm{~g} \mathrm{~kg}^{-1}$ de solo; classe 2, argila de 550-400 $\mathrm{g} \mathrm{kg}^{-1}$ de solo; classe 3, argila de $400-110 \mathrm{~g} \mathrm{~kg}^{-1} \mathrm{de} \mathrm{solo.}^{(2)} \mathrm{Valor}^{-}$ superior da faixa corresponde ao teor crítico ajustado.

29,7 e $63,7 \mathrm{~kg}$ para soja, trigo e milho, respectivamente. A soja tem sistema radicular menos abundante do que o trigo e o milho, provavelmente com menor eficiência de absorção de P.

A diferença das doses de $\mathrm{P}_{2} \mathrm{O}_{5}$ entre os métodos (Quadro 7) é aparente, pois estes possuem faixas de fertilidade com diferentes amplitudes e as doses foram obtidas pela divisão da quantidade estimada de $\mathrm{P}_{2} \mathrm{O}_{5}$ necessária para produção de $90 \%$ pelo teor críti- co de P nesse ponto, obtido pelos métodos Mehlich-1, Mehlich-3 e resina no tratamento sem o fertilizante testado. A quantidade de $\mathrm{P}_{2} \mathrm{O}_{5}$ necessária para cada cultura foi dividida pelo teor intermediário de cada faixa de fertilidade e dentro de cada classe textural, em todos os métodos. Dessa forma, os métodos que extraem menos $\mathrm{P}$ do solo, como o Mehlich-1, possuem intervalos de faixas de fertilidade e teor crítico menores do que, por exemplo, o Mehlich-3. Assim, os valores para elevar o P em $1 \mathrm{mg} \mathrm{kg}^{-1}$ de solo são maiores (Quadro 7). 
Quadro 7. Quantidade de $\mathrm{P}_{2} \mathrm{O}_{5}$ estimada para elevar o $\mathrm{P} \mathrm{em} 1 \mathrm{mg} \mathrm{kg}^{-1}$ no solo, para obtenção do rendimento relativo de $90 \%$, nas culturas de soja, trigo e milho sob sistema plantio direto, em solos de diferentes classes texturais, profundidade de amostragem e métodos de análise

\begin{tabular}{|c|c|c|c|c|c|c|}
\hline \multirow{2}{*}{ Cultura } & \multicolumn{3}{|c|}{ Profundidade $0-20 \mathrm{~cm}$} & \multicolumn{3}{|c|}{ Profundidade $0-10 \mathrm{~cm}$} \\
\hline & Classe 1 & Classe 2 & Classe 3 & Classe 1 & Classe 2 & Classe 3 \\
\hline & \multicolumn{6}{|c|}{$-\mathrm{kg} \mathrm{ha}^{-1}$} \\
\hline & \multicolumn{6}{|c|}{ Mehlich - 1} \\
\hline Soja & 35,4 & 12,0 & 10,0 & 19,0 & 11,8 & 6,0 \\
\hline Trigo & 27,2 & 10,4 & 7,5 & 17,0 & 7,9 & 4,8 \\
\hline Milho & 30,8 & 12,0 & 7,0 & 15,7 & 7,0 & 4,5 \\
\hline \multirow[t]{2}{*}{ Média } & 31,1 & 11,5 & 8,2 & 17,2 & 8,9 & 5,1 \\
\hline & \multicolumn{6}{|c|}{ Mehlich - 3} \\
\hline Soja & 24,4 & 7,6 & 4,3 & 16,9 & 5,9 & 3,5 \\
\hline Trigo & 16,0 & 5,6 & 3,3 & 12,0 & 4,3 & 3,3 \\
\hline Milho & 15,4 & 5,0 & 3,0 & 10,3 & 3,5 & 3,0 \\
\hline \multirow[t]{2}{*}{ Média } & 18,6 & 6,1 & 3,5 & 13,1 & 4,6 & 3,3 \\
\hline & \multicolumn{6}{|c|}{ Resina } \\
\hline Soja & 11,8 & 6,0 & 3,7 & 8,4 & 4,2 & 3,0 \\
\hline Trigo & 14,4 & 7,5 & 5,2 & 8,9 & 5,6 & 4,3 \\
\hline Milho & 10,1 & 6,0 & 4,8 & 7,2 & 4,4 & 4,0 \\
\hline Média & 12,1 & 6,5 & 4,6 & 8,2 & 4,7 & 3,8 \\
\hline
\end{tabular}

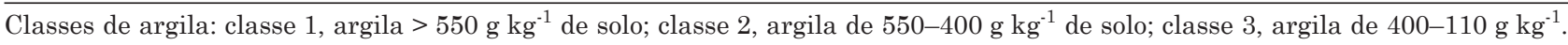
$\mathrm{R}$ : reposição das quantidades exportadas pelos grãos.

As diferentes doses de $\mathrm{P}_{2} \mathrm{O}_{5}$ para as classes texturais são esperadas (Siqueira et al., 1987; CFSRS/ SC, 1995, 2004), uma vez que parte do P aplicado como fertilizante é adsorvida a óxidos e hidróxidos de Fe e $\mathrm{Al}$, que estão presentes em maiores quantidades nos solos mais argilosos.

As doses de fertilizantes sugeridas para as culturas nas futuras análises de solo (considerando-se as classes texturais, no caso do P) são obtidas subtraindo-se o valor intermediário da faixa de fertilidade do nutriente em questão do valor de teor crítico (Quadro 6) e multiplicando-se o valor obtido pela quantidade de $\mathrm{P}_{2} \mathrm{O}_{5}$ necessária para elevar em $1 \mathrm{mg} \mathrm{kg}^{-1}$ de solo (Quadro 7). Os valores médios encontrados (Quadro 8) são oriundos das médias dos diferentes métodos e profundidade de amostragem. As doses estimadas de $\mathrm{P}_{2} \mathrm{O}_{5}$ (Quadro 8) são diferentes entre as culturas em razão das suas diferentes necessidades (Raij et al., 1997; CFSRS/SC, 2004) e eficiência de utilização dos fertilizantes.

A primeira etapa da calibração tem por objetivo estimar o grau de deficiência ou suficiência de nutrientes para as plantas. Pode ser feita por vários métodos, obedecendo logicamente aos critérios de eficiência do método, praticidade de execução em laboratório e economicidade nas análises.

Os solos do RS apresentam grandes diferenças na constituição química, física e mineralógica. Podem ser fertilizados com produtos de diferentes reatividades,
Quadro 8 Dose média de $\mathrm{P}_{2} \mathrm{O}_{5}$ estimada para produção de $90 \%$ do rendimento máximo de soja, trigo e milho sob sistema plantio direto de cultivo no RS, em diferentes faixas de fertilidade e classes de argila

\begin{tabular}{|c|c|c|c|}
\hline Faixa de fertilidade & Classe 1 & Classe 2 & Classe 3 \\
\hline & & $\mathrm{kg} \mathrm{ha} \mathrm{h}^{-1}$ & - \\
\hline & & Soja & \\
\hline Muito baixo & 195 & 160 & 135 \\
\hline Baixo & 110 & 90 & 70 \\
\hline Médio & 35 & 30 & 30 \\
\hline Alto & $\mathrm{R}$ & $\mathrm{R}$ & $\mathrm{R}$ \\
\hline \multirow[t]{2}{*}{ Muito alto } & $\mathrm{R}$ & $\mathrm{R}$ & $\mathrm{R}$ \\
\hline & & Trigo & \\
\hline Muito baixo & 165 & 140 & 130 \\
\hline Baixo & 100 & 80 & 75 \\
\hline Médio & 35 & 30 & 30 \\
\hline Alto & $\mathrm{R}$ & $\mathrm{R}$ & $\mathrm{R}$ \\
\hline \multirow[t]{2}{*}{ Muito alto } & $\mathrm{R}$ & $\mathrm{R}$ & $\mathrm{R}$ \\
\hline & & Milho & \\
\hline Muito baixo & 150 & 125 & 125 \\
\hline Baixo & 90 & 70 & 70 \\
\hline Médio & 35 & 30 & 30 \\
\hline Alto & $\mathrm{R}$ & $\mathrm{R}$ & $\mathrm{R}$ \\
\hline Muito alto & $\mathrm{R}$ & $\mathrm{R}$ & $\mathrm{R}$ \\
\hline
\end{tabular}

Classes de argila: classe 1, argila $>550 \mathrm{~g} \mathrm{~kg}^{-1}$ de solo; classe 2, argila de 550-400 $\mathrm{g} \mathrm{kg}^{-1}$ de solo; classe 3, argila de 400$110 \mathrm{~g} \mathrm{~kg}^{-1}$. R: reposição das quantidades exportadas pelos grãos. 
como, por exemplo, os fosfatos naturais que se solubilizam em contato com a solução ácida de Mehlich-1, superestimando a disponibilidade de P para as plantas (Raij, 1991; Kroth, 1998). Assim, os métodos de análise de solo podem estimar de modo diferenciado a quantidade necessária de nutrientes para as plantas, sendo importante apenas escolher aquele que melhor se adapta ao tipo de solo e ao manejo adotado.

A segunda etapa da calibração tem por objetivo quantificar as doses necessárias para produção de máxima eficiência econômica (neste caso). Esta etapa deve ser simples, para facilitar as recomendações, e não apresenta razões para dosagens específicas para cada método de análise de solo e em cada profundidade de amostragem. Ao contrário, a elaboração de doses médias para os três métodos (Mehlich-1, Mehlich-3 e resina) e as duas profundidades de amostragem (0-20 e $0-10 \mathrm{~cm}$ ) pode amenizar possíveis distorções devidas à variabilidade nos valores das análises de solo e respostas das culturas, nos cálculos da elaboração das doses de $\mathrm{P}_{2} \mathrm{O}_{5}$ para as culturas na segunda etapa da calibração.

Assim, dependendo do tipo de solo, do tempo de adoção do sistema plantio direto, das doses e dos modos de aplicação de fertilizantes, que influem na estratificação da fertilidade do solo, o usuário do sistema pode amostrar o solo na profundidade de $0-20$ ou $0-10 \mathrm{~cm}$ utilizando qualquer método (Mehlich-1, Mehlich-3 ou resina), que a calibração irá enquadrar o teor da análise em uma faixa de fertilidade (muito baixo, baixo, médio, alto ou muito alto) e a recomendação será única para qualquer método ou profundidade. Na realidade, as plantas absorvem os nutrientes do solo em várias profundidades do perfil e os métodos têm por objetivo apenas correlacionar os teores determinados por eles com o o rendimento das culturas.

As doses de $\mathrm{P}_{2} \mathrm{O}_{5}$ foram definidas para $90 \%$ do rendimento de máxima eficiência técnica das culturas sob sistema plantio direto. Pressupõe-se que com essa dose o teor do nutriente no solo seja elevado até o teor crítico estimado. Essas doses são para apenas um cultivo e podem não ser economicamente viáveis, especialmente na faixa de fertilidade "muito baixo", que exige altas doses de $\mathrm{P}$, devido às variações de preços dos insumos ( $\mathrm{kg}$ de $\left.\mathrm{P}_{2} \mathrm{O}_{5}\right)$ e dos grãos das culturas (kg de soja, trigo ou milho). O rendimento, esperado em 90 \% do máximo, pode também não ser obtido em razão do modo de aplicação do adubo e da interação deste com os processos químicos, físicos e biológicos que influenciam na nutrição das plantas. Há ainda o efeito de outros fatores de produção do solo, do clima, da cultura e do manejo.

No caso de comparação com doses recomendadas por outros sistemas de recomendação, devem-se acrescentar as quantidades de $\mathrm{P}_{2} \mathrm{O}_{5}$ exportadas pelos grãos e perdidas no sistema (CFSRS/SC, 2004). Os rendimentos da soja, do trigo e do milho $(90 \%$ do rendimento de máxima eficiência técnica) com adição de $\mathrm{P}_{2} \mathrm{O}_{5}$ foram de 2,7, 2,2 e 5,6 t ha-1, obtidos pelo uso das equações de regressão polinomiais médias do quadro 1, e a exportação estimada foi de 38, 22 e $45 \mathrm{~kg} \mathrm{ha}^{-1}$ ano $^{-1}$, respectivamente (baseada em CFSRS/SC, 2004).

As doses de $\mathrm{P}_{2} \mathrm{O}_{5}$ (Quadro 8) sugeridas para a soja e o milho sob sistema plantio direto de cultivo são, em geral, maiores neste trabalho do que as doses para as mesmas faixas de fertilidade das recomendações para os sistemas plantio direto e convencional, sugeridas pela CFSRS/SC (1995, 2004). Provavelmente, isso se deve à maior necessidade de exportação nas variedades com maior potencial genético de produção, cultivadas atualmente. No caso do trigo, as doses recomendadas neste trabalho são menores que as recomendadas pela CFSRS/SC (1995, 2004).

A cultura do trigo tem a melhor eficiência de utilização dos fertilizantes fosfatados obtendo-se rendimentos elevados de grãos com doses pequenas de $\mathrm{P}_{2} \mathrm{O}_{5}$ (Quadro 1), o que se deve à baixa necessidade de $\mathrm{P}$ e K nas plantas inteiras (Raij et al., 1997) e à baixa exportação pelos grãos (Raij et al., 1997; CFSRS/ SC, 2004). O lucro obtido com a cultura do trigo sob sistema plantio direto de cultivo, para produção de $2.400 \mathrm{~kg} \mathrm{ha}^{-1}$, é menor $\left(2,4 \mathrm{US} \$ \mathrm{ha}^{-1}\right)$ que o obtido com milho (111,75 US $\$$ ha $^{-1}$, para produção de milho de apenas $\left.4500 \mathrm{~kg} \mathrm{ha}^{-1}\right)$ e com soja $\left(152,80 \mathrm{US} \$ \mathrm{ha}^{-1}\right.$, para produção de soja de $2.400 \mathrm{~kg} \mathrm{ha}^{-1}$ ). Foram considerados os custos de produção médios de sete anos e o preço médio de soja, trigo e milho de 13 anos (FECOAGRO, 2004).

\section{CONCLUSÕES}

1. Os coeficientes de determinação entre o rendimento relativo das culturas e os teores de $\mathrm{P}$ no solo aumentam quando se separam os solos por classes texturais e são maiores na camada de $0-10 \mathrm{~cm}$ de profundidade.

2. Os teores críticos de $\mathrm{P}$ em solos sob sistema plantio direto de cultivo com soja, trigo e milho são maiores do que os estabelecidos para os solos do Rio Grande do Sul, tanto para solos amostrados na camada de 0-20 cm como na de 0-10 cm de profundidade.

3. Os métodos da resina e Mehlich-3 apresentaram faixas de fertilidade mais amplas do que o método Mehlich-1.

4. As doses de fertilizantes fosfatados para as culturas de soja e milho, obtidas neste trabalho em sistema plantio direto, considerando-se a produção de 90 \% do rendimento máximo, são maiores do que as recomendadas atualmente pelo Sistema de Recomendação de Adubação e Calagem para os Estados do Rio Grande do Sul e Santa Catarina, obtidas por calibração em sistema convencional de cultivo. 


\section{AGRADECIMENTOS}

Às instituições de ensino, pesquisa e extensão do Rio Grande do Sul, que gentilmente cederam amostras de solos de seus experimentos e os dados de rendimento de grãos.

\section{LITERATURA CITADA}

ANGHINONI, I. \& VOLKWEIS, J.S. Recomendaç̃es de uso de fertilizantes. In: SIMPÓSIO SOBRE FERTILIZANTES NA AGRICULTURA BRASILEIRA, 1984, Brasília. Anais. Brasília, Embrapa/DEP, 1984. p.179-204.

BRAIDA, J.A.; CAMARGO, F.A.O.; ROSSO, I.J.; GIANELLO, C. \& MEURER, E. J. Comparação de métodos de determinação da disponibilidade de fósforo do solo para as plantas. R. Bras. Ci. Solo, 20:345-347, 1996.

CATE, R.B. \& NELSON, L.A. Discontinuous models for rapid correlation, interpretation and utilization of soil analysis and fertilizer response data. International soil fertility evaluation and improvement program [S.l.], North Carolina, 1973. 77p. (Technical Bulletin, 7)

COMISSÃO DE FERTILIDADE DO SOLO - CFSRS/SC. Recomendações de adubação e calagem para os estados do Rio Grande do Sul e Santa Catarina. 2. ed. Passo Fundo, SBCS - Núcleo Regional Sul, EMBRAPA/CNPT, 1989. 128 p.

COMISSÃO DE FERTILIDADE DO SOLO - CFSRS/SC. Manual de adubação e de calagem para os estados do Rio Grande do Sul e Santa Catarina. 10.ed. Porto Alegre, Sociedade Brasileira de Ciência do Solo, Núcleo Regional Sul; UFRGS, 2004. 400p.

COMISSÃO DE FERTILIDADE DO SOLO - CFSRS/SC Recomendações de adubação e calagem para os estados do Rio Grande do Sul e Santa Catarina. 3.ed. Passo Fundo, Sociedade Brasileira de Ciência do Solo, Núcleo Regional Sul; Embrapa/CNPT, 1995. 224p.

ELTZ, F.L.P.; PEIXOTO, R.T.G. \& JASTER F. Efeitos de sistemas de preparo do solo nas propriedades físicas e químicas de um latossolo bruno álico. R. Bras. Ci. Solo, 13:259-267, 1989

EMATER/RS. Área plantada e rendimento das principais culturas. Porto Alegre, DEPLAN/DIDOC, 1998. (Quadros não publicadas).

EMATER/RS. Resultados das safras desde 1941: consulta das médias estaduais. Disponível em: <http:// www.emater.tche.br>. Acesso em 20 de set. de 2005.

EVANS, E.E. Soil test calibration. In: BROWN, J.R., ed. Soil testing: Sampling, correlation, calibration end interpretation. Madison, Soil Science Society of America, 1987. p.23-29 (Special Publication, 21).

FEDERAÇÃO DAS COOPERATIVAS AGROPECUÁRIAS DO RIO GRANDE DO SUL - FECOAGRO/RS. Custo de produção, lavouras em plantio direto. Porto Alegre, 2004. $35 \mathrm{p}$.
INSTITUTO BRASILEIRO DE GEOGRAFIA E ESTATÍSTICA - IBGE. SIDRA - Banco de dados agregados. Disponível em: <http://www.sidra.ibge.gov.br > Acesso em 20 de set. de 2005 .

KAMPRATH, E.J. \& WATSON, M.E. Conventional soil and tissue test for assessing the phosphorus status of soil. In: KHASAWNEH, F.E.; SAMPLE, E.C. \& KAMPRATH, E.J., eds. The role of phosphorus in agriculture. Madison, American Society of Agronomy, 1980. p.433-469.

KROTH, P.L. Disponibilidade de fósforo no solo para as plantas e fatores que afetam a extração por resina de troca em membranas. Porto Alegre, Universidade Federal do Rio Grande do Sul, 1998. 167p. (Tese de Mestrado)

KUSSOW, W.R.; CORUM, K.R. \& DALL'ACQUA, F.M. Interpretação agro-econômica de ensaios de adubação. Goiânia: Embrapa, 1976. 49p. (Boletim Técnico, 4)

MANUAL de adubação e calagem para cultivos agrícolas do Rio Grande do Sul e Santa Catarina. Trigo e Soja, 56:134, 1981.

MEHLICH, A. Mehlich-3 soil test extractant: A modification of Mehlich 2 extractant. Comm. Soil Sci. Plant Anal., 15:1409$1416,1984$.

MIELNICZUK, J. \& SELBACH, P.A. Capacidade de suprimento de potássio de seis solos do Rio Grande do Sul. R. Bras. Ci. Solo, 2:115-120, 1978.

MIOLA, G.R. Extração de P, K, Ca e mg do solo por diferentes métodos e avaliação da disponibilidade de $\mathrm{P}$ para as plantas. Porto Alegre, Universidade Federal do Rio Grande do Sul, 1995. 127p. (Tese de Mestrado)

OLIVEIRA, V. Formas de potássio em 21 solos do Rio Grande do Sul e sua capacidade de suprir potássio às plantas. Porto Alegre, Universidade Federal do Rio Grande do Sul, 1970. 91p. (Tese de Mestrado)

QUADROS de adubação corretiva e adubação de manutenção para solos e culturas dos estados do Rio Grande do Sul e Santa Catarina. Trigo e Soja, 10:15-23, 1976.

RAIJ, B. van. Fertilidade do solo e adubação. Piracicaba, Ceres, Potafos, 1991. 343p.

RAIJ, B.van; CANTARELLA, H.; QUAGGIO, J.A. \& FURLANI, A.M.C. Recomendações de adubação e calagem para o estado de São Paulo. 2.ed. Campinas, Instituto Agronômico/Fundação IAC, 1997. 285p. (Boletim Técnico, 100).

RAIJ, B.van; QUAGGIO, J.A. \& SILVA, M.N. Extraction of phosphorus, potassium, calcium and magnesium from soil by an ion-exchange resin procedure Comm. Soil Sci. Plant Anal., 17:547-566, 1986.

REIN, T.A. Estimativa do fluxo difusivo de fósforo nos solos e avaliação de sua disponibilidade às plantas. Porto Alegre, Universidade Federal do Rio Grande do Sul, 1991. 170p. (Tese de Mestrado) 
ROUSE, R.D. Soil test theory and calibration for cotton, corn, soybean and coastal Bermuda grass. Auburn, Agricultural Experiment Station Auburn University, 1968. 65p. (Technical Bulletin, 375)

SCHLINDWEIN, J.A. Calibração de métodos de determinação de fósforo e potássio do solo sob sistema plantio direto. Porto Alegre, Universidade Federal do Rio Grande do Sul, 2003. 169p. (Tese de Doutorado)

SCHLINDWEIN, J.A. \& ANGHINONI, I. Variabilidade vertical de fósforo e potássio disponíveis e profundidade de amostragem do solo no sistema plantio direto. Ci. Rural, 30:611-617, 2000 .

SCHLINDWEIN, J.A. \& GIANELLO, C. Doses de máxima eficiência econômica de fósforo e potássio para as culturas cultivadas no sistema plantio direto. R. Plantio Direto, 85:20-25, 2005 .

SCHLINDWEIN, J.A. \& GIANELLO, C. Necessidades de novos estudos de calibração e recomendações de fertilizantes para as culturas sob sistema plantio direto. R. Plantio Direto, 79:12-15, 2004.
SILVA, W.M.; FABRICIO, M.C. \& MARChETTI, M.E. Extratores de fósforo em dois Latossolos do Mato Grosso do Sul. In: CONGRESSO BRASILEIRO DE CIÊNCIA DO SOLO, 26., Rio de Janeiro, 1997. Anais. Rio de Janeiro, Sociedade Brasileira de Ciência do Solo, 1997. 3p. CDROM.

SIQUEIRA, O.J.F.; SCHERER, E.E. \& TASSINARI, G. Recomendações de adubação e calagem para os estados do Rio Grande do Sul e Santa Catarina. Passo Fundo, Embrapa/CNPT, 1987. 100p.

TEDESCO, M.J.; GIANELLO, C. \& BISSANI, C.A. Análise de solo, plantas e outros materiais. 2.ed. Porto Alegre, Universidade Federal do Rio Grande do Sul, 1995. 147p. (Boletim Técnico, 5).

UNIVERSIDADE FEDERAL DO RIO GRANDE DO SUL UFRGS. Quadros de adubação corretiva e adubação de manutenção para os solos e culturas dos estados do Rio Grande do Sul e Santa Catarina. Porto Alegre, 1973. 11p. (Boletim Técnico) 